\title{
THE INFLUENCE OF FARMERS' SOCIAL AND ECONOMIC CAPITAL ON THE DEVELOPMENT OF BEEF FARMING GROUP IN JAMBI PROVINCE, INDONESIA
}

\author{
Firmansyah*, Maruli Pahantus, Hoesni Fachroerrozi, Afriani H. \\ Faculty of Animal Science, University of Jambi, Indonesia \\ *E-mail: firmansyah fapet@yahoo.co.id
}

\begin{abstract}
The purpose of this study was to determine the effect of social and economic capital on the development of cattle herds in Jambi Province. The sampling technique used in this research is Cluster Random Sampling, namely as clusters are Tebo Regency and Muaro Jambi Regency. The sample size in this study was determined using the iterative method. To determine the effect of social and economic capital on the development of cattle herds in Jambi Province, StepWise Multiple Regression analysis was used. The social capital of cattle farmer groups in the form of trust and social networks partially influences the development of farmer groups in Jambi Province. Meanwhile, the economic capital of the cattle farmer group is in the form of:cattle farming costs partially affect the development of farmer groups in Jambi Province.
\end{abstract}

\section{KEY WORDS}

Social capital, farmer groups, cattle.

The capacity of breeders in carrying out livestock activities, apart from the knowledge and skills of individual farmers in processing businesses and marketing livestock products, is no less important than the collective capacity of farmers in all livestock activities. This collective capacity of farmers is possible if the community of farmers has large enough social capital. Social capital is an ability that arises from the prevalence of trust in a society or in certain parts of society. People who trust each other will be better at organizational innovation because high trust allows the emergence of a wide range of social relationships. Positive expansion of social capital, especially in communities with limited economic capital, consequently will result in an increase in economic performance and an increase in the quality of life (Carpenter, 2004). As in livestock economic activities, the erosion of social capital will reduce the collective capacity of farmers, which in turn will further reduce the performance of livestock activities.

In general, experts agree that the main sources of cultivating social capital in a society are social and cultural factors, as well as the community's experience in interacting with other parties, in addition to physical and economic factors where the community is located (Fukuyama 1995; Colletta, 2003). 1998; Coleman, 2000; Lin, 2001). Social and cultural factors are indicated by cultural values, religion, traditions, and the existence of the same norms, family relations, kinship and neighbors, as well as existing social and economic relations. The experience of the community in interacting with other parties can be in the form of good social relations experiences so as to further enhance social relations.

One of the institutions that encourage the development of cattle farming at the rural level of Jambi Province is a livestock farmer group which is managed "from the farmer by the farmer and for the farmer". However, in reality, the current condition of cattle farmer groups at the rural level is still very weak, especially in accessing business activities for farmers for various reasons, especially social and economic capital.

The development of cattle farmer groups is a vehicle and process for exchanging information and becoming a social network among cattle farmers. In addition to the institutional development of breeders (livestock farmer groups are expected to bring changes in behavior for cattle farmers in increasing their business). Institutional breeders (livestock farmer groups) have the following functions: as a forum for the learning process, a vehicle for 
cooperation, units providing production facilities and infrastructure, production units, processing and marketing units, and supporting service units. Apart from that, farmer institutions (cow farmer groups) are also a vehicle for sustainable social and economic capital for cattle farmers.

The sustainability of the cattle group business requires the existence of social and economic capital which is the foundation of the business. One of the elements of social capital needed in groups is the nature and attitude to trust each other and can be trusted in cooperative relationships so that among group members have a high level of trust. Trust is a very important capital to build a network of partnerships (cooperation) with external parties. Cooperation based on trust will occur if it is based on honesty, fairness, openness, mutual care, mutual respect and mutual help among group members. Parties outside the group will also provide support, assistance and cooperation to the group if the group can be trusted.

In addition to social capital, economic capital is also very important in cattle farming. Economic capital (financial capital) is a form of wealth in the form of money or goods that are used to produce something either directly or indirectly in the production process. The capital of the breeder outside the land is livestock and their cages, hoes, plows and other agricultural tools, fertilizers, seeds, crops that have not been sold. According to Wijaya (2007) that economic capital is something that must be considered before doing a business. Economic capital can also be in the form of capital or assets, revenues and costs that will be incurred when production activities take place.

\section{METHODS OF RESEARCH}

The research method used in this study is a survey method, namely a comprehensive examination or research. Surveys conducted in research are usually carried out by distributing questionnaires or interviews. Surveys are commonly conducted in both quantitative and qualitative research. In quantitative research, surveys are more of a closed question, while in qualitative research it is in-depth interviews with open questions. This research was carried out in 2 districts in Jambi Province, namely Tebo Regency and Muaro Jambi Regency.

The sampling technique used in this study is Cluster Random Sampling, namely as clusters are Tebo Regency and Muaro Jambi Regency. The sample size in this study was determined using the iterative method (Harun Al Rasyid, 1994). The first step to obtain a sample, first is to calculate the total sample size to be taken through:

$$
n=\frac{\left(Z_{1-\alpha}+Z_{1-\beta}\right)^{2}}{\left(U_{p}^{\prime}\right)^{2}}+3
$$

Where:

$Z_{1-\alpha}=$ constant obtained from the normal distribution table;

$z_{1-\beta}=$ constant obtained from the normal distribution table;

$\alpha=$ type I error, accepting a hypothesis that should be rejected;

$\beta=$ type II error, rejecting the hypothesis that should be accepted;

$\rho=$ estimated price correlation coefficient.

Validity is a measure that shows the level of authenticity of a measuring instrument. Validity test is carried out by: a) adjusting the content of the questions to the respondent's condition, b) adjusting to what previous researchers have done to obtain the same data, c) considering the theories and facts that have been expressed by experts from various libraries and d) considering advice-advice from experts and supervisors (Rosana et al, 2010). Test the validity of the questionnaire measuring instrument using the Pearson Product Moment Correlation formula based on Singarimbun and Effendy (1995) as follows: 


$$
r_{X Y}=\frac{n \sum X Y-\left(\sum X\right)\left(\sum X\right)}{\sqrt{\left\{n \sum X^{2}-\left(\sum X\right)^{2}\right)\left(n \sum Y^{2}-\left(\sum Y\right)^{2}\right\}}}
$$

Where:

$r_{x y}=$ Coefficient of validity $x y$;

$X=$ Score of each variable;

$\mathrm{Y}=$ Variable (economic and non-economic);

$\mathrm{n}=$ Number of questions.

Reliability is the degree of accuracy, precision or accuracy shown by the measuring instrument. To determine the instrument reliability coefficient (Cronbach) can use the following formula:

$$
\mathrm{r} 11=\left[\frac{k}{k-1}\left[1-\frac{\sum \sigma h^{2}}{\sigma 1^{2}}\right]\right]
$$

Where: $\mathrm{r} 11=$ instrument reliability, $1=$ constant, $\mathrm{k}=$ many questions.

To know the difference social and economic capital on the development of cattle herds between Muaro Jambi Regency and Tebo Regency using the t test with the formula:

$$
t-\text { hitung }=\frac{\overline{X_{1}}-\overline{X_{2}}}{\sqrt{\frac{S_{1}^{2}}{n_{1}}+\frac{S_{2}^{2}}{n_{2}}}}
$$

Where:

$\overline{X_{1}}=$ Average social and economic capital of cattle farmer groups in Muaro Jambi Regency;

$\overline{X_{2}}=$ Average social and economic capital of cattle farmer groups in Tebo Regency;

$S_{1}^{2}=$ Variance of the level of social and economic capital of cattle farmer groups in Muaro Jambi Regency;

$S_{2}^{2}=$ Variance of the level of social and economic capital of cattle farmer groups in Tebo Regency;

$n_{1} \quad=\quad$ Number of samples of cattle farmer group members in Muaro Jambi Regency;

$n_{2} \quad=$ Number of samples of cattle farmer group members in Tebo Jambi Regency.

To determine the effect of social and economic capital on the development of cattle herds in Jambi Province StepWise Multiple Regression analysis was used. The stepwise multiple regression model for social capital is formulated:

$$
Y \text { spi }=\alpha+\beta_{1} X_{1}+\beta_{2} X_{2}+\beta_{3} X_{3}+\beta_{4} X_{4}+\beta_{5} D+\varepsilon
$$

Where:

Y: Cattle group development;

$\mathrm{X} 1$ : Trust;

$\mathrm{X} 2$ : Social network;

X3: Reciprocal relationship;

X4: Norm;

D1: Muaro Jambi Regency;

D2: Tebo Regency;

$\alpha$ : Intercept coefficient;

$\beta 1-4$ : Variable coefficient X1 - X4;

e: Residual or confounding variable (error term).

The stepwise multiple regression model for economic capital is formulated:

$$
Y s p i=\alpha+\beta_{5} X_{5}+\beta_{6} X_{6}+\beta_{7} X_{7}+\beta_{8} X_{8}+\beta_{9} D+\varepsilon
$$


Where:

Y: Cattle group development;

X5: Group assets;

X6: Income;

X7: Cattle price;

X8: Production cost;

D1: Muaro Jambi Regency;

D2: Tebo Regency;

a: Intercept coefficient;

a5-8: Variable coefficient X5 - X8;

e: Residual or confounding variable (error term).

Before testing the hypothesis, it is necessary to carry out an overall test to determine the effect of the independent variables together on the dependent variable, namely the $F$ test. The $F$ test is useful for statistically proving that the overall regression coefficient is significant in influencing the value of the dependent variable. If the regression parameter value $=0$ it can be concluded that there is no linear relationship between the dependent variable and the independent variable.

\section{RESULTS AND DISCUSSION}

The development of the concept of social capital began in the mid-1990s (Patrick et al., 2006). The World Bank in its annual report entitled Entering the $21^{\text {st }}$ Century, revealed that social capital has a significant impact on development processes (World Bank, 2000). Development activities will be easier to achieve and less costly if there is a large amount of social capital (Narayan and Prittchett 1997; Grootaert and Van Bastelaer, 2002). According to Tonkiss (2000), social capital is only economically valuable if it can help individuals or groups, for example, to access financial resources, obtain information, work, start a business, and minimize transaction costs. In fact, social networks, as part of social capital,

In his research in Indonesia (Grootaert, 2001) found the fact that the contribution of social capital in increasing household income in Jambi, Central Java, and East Nusa Tenggara is proportional to the contribution of human capital. In addition, social capital also helps households overcome risks due to income fluctuations or in other words, social capital is an alternative to overcome the problem of household poverty. In social capital, it emphasizes the potential of groups and between groups with space for attention to social networks, norms, values, and beliefs between people that are born from group members and become group norms. Social capital includes good will, a sense of friendship, mutual sympathy, as well as social relations and close cooperation between individuals and families that form a social group (Syabra, 2003).

The income distribution gap remains constant. The gap is perceived as an injustice which will then reduce the level of public trust in the government, especially distrust in the good will and ability of the government to manage natural resources for the greatest prosperity of the people and create equitable development. Whereas trust, as one of the components of social capital, is a factor that cannot be ignored anymore in an effort to achieve development success. Mutual trust plays an important role in creating healthy economic development and reducing transaction costs, while other components of social capital, namely organizational density and community participation, will increase people's access to welfare sources such as access to business capital, employment and others (Grootaert, 2001). Vipriyanti (2011) asserts that economic growth cannot be realized without changes in social organization and value systems because the productivity of an economic system is conditioned by the culture and institutions that exist in the community where the accumulation of trust occurs through personal interactions in a community. will increase efficiency and reduce costs.

Cohen and Prusak (2001), every relationship pattern that occurs is bound by mutual understanding, and shared values that bind group members to make the possibility of collective action to be carried out effectively and efficiently. When beliefs and beliefs 
dominate individuals and groups, it will be possible to create responsible lives among human beings so that they can act responsibly and will strengthen group solidarity. People can only be present in a trusted environment so that people cannot interpret accurately, cannot be responsible, and cannot create solidarity outside their circle of belief.

In this study, social capital in the form of trust consists of the trust of farmers to cooperate with members of their farmer groups, the ability of farmers to cooperate with other farmer groups, trust of farmers to maintain relationships between groups. The results of the study found that most of them said they believed they could work together between farmers and members of their farmer groups $(60.81 \%)$. Then it was found that the majority of farmers $(58.11 \%)$ were still less able to cooperate with other members of farmer groups. Another result was that the farmers stated that they did not believe that they could maintain the relationship between groups, namely $28.38 \%$ and $16.22 \%$, respectively. According to Helliwel (2006), life satisfaction is related to various types of trust and also networks that may support trust

Determination of social capital is actually not limited to cognitive dimensions such as trust and local norms, but also structural factors which include networks and institutions (Grootaert and Van Bastelaer 2002). The structural dimension is related to membership in the group.Social networks owned by farmers include knowledge of farmers about members of their farmer groups, the formation of networks between farmers and members of their farmer groups, as well as networks formed between farmers and other farmer groups. The results of the study found that most of the farmers stated that they knew other group members $(68.92 \%)$, but in reality there was no network formed between group members (72.98\%) or between groups (77.03\%). according toStimson et al., (2009) social capital has emerged as a non-economic concept that is attracting attention as an important way of thinking about the role of intangible development factors, such as institutions, networks and trust in regional economic development. According to Putnam (1995) that social networks can be considered important in the formation of social capital. The existence of networks of social relations between individuals in social capital provides benefits in the context of managing shared resources because it facilitates coordination and cooperation for mutual benefits.

Social capital is always colored by the tendency to exchange favors between individuals in a group or between groups themselves. The reciprocal relationships in this study include mutual help, mutual care and mutual concern. The results of the study found that half of the respondents helped each other while the rest did not help each other between farmers. In addition, the majority of breeders lack and do not care about each other between breeders $(62.16 \%)$, and breeders pay less attention to each other between breeders (62.16\%). according toCarpenter (2004), social capital is a resource that exists in individuals who come from group interactions because of trust, reciprocity, and cooperation. Social capital that exists in society describes the process of social interaction in terms of access to social networks and participation in groups (Woolcock and Narayan, 2000).

The system of norms and values that developed in the Kuang Village community is a system of values or customs that has developed from the past.Norms are a set of rules that are expected to be obeyed and followed by the community in a particular social entity. Norms in this study include group rules, group sanctions and wise leader decisions. The results of the study found that the majority of the rules in the group were still lacking (56.6\%), the sanctions in the group were still lacking $(63.51 \%)$, the decision of the group leader was not wise $(58.11 \%)$. According to Hasbullah (2006), norms are a set of rules that are expected to be obeyed and followed by the community in a particular social entity. These rules are usually not written but are understood as determining patterns of good behavior in the context of social relations so that social sanctions are given if they are violated.

The results of the regression analysis obtained the $R^{2}$ value of 0.466 . Then the results of the $F$ test analysis obtained the value of $F_{\text {count }}=1.217$ with sig. 0.001 . These results indicate that trust, social networks, reciprocal relationships, norms and regions simultaneously affect the development of farmer groups in Jambi Province. Then a t-test was 
carried out to see partially which results were that trust and social networks partially affected the development of farmer groups in Jambi Province.

Social capital is productive in providing material benefits to individuals who are linked to other individuals and groups (Bourdieau, 1985; Coleman, 1990; Putman, 1993). According to Sawitri and Soepriadi (2014), Social capital is also an important factor that greatly influences the level of productivity of post-production agricultural product sales. In addition, trade cannot be separated from the availability of networks where social capital is an important factor that can open networks between agricultural actors and other parties with an interest in agricultural activities and products, including private sector institutions and government institutions. The practice of trading agricultural products often does not fully benefit the producers so that the role of social capital among agricultural actors becomes very important to help encourage the bargaining position of agricultural actors to be better.

Economic capital is a form of wealth in the form of money or goods that are used to produce something either directly or indirectly in the production process. In this study, economic capital consists of group assets, cattle business costs, cattle business income, and cattle selling prices. The results of the regression analysis obtained the $R^{2}$ value of 0.328 . Then the results of the analysis of the $F$ test obtained the value of $F_{\text {count }}=2,527$ with sig. 0.004. These results indicate that group assets, cattle business costs, cattle business income, and cattle selling pricesimultaneously affect the development of farmer groups in Jambi Province. Then a t-test was carried out to see partially which results werecattle farming costspartially affect the development of farmer groups in Jambi Province. According to Wijaya (2007) that economic capital is something that must be considered before doing a business. Economic capital can also be in the form of capital or assets, revenues and costs that will be incurred when production activities take place.

\section{CONCLUSION}

The social capital of cattle farmer groups in the form of trust and social networks partially influences the development of farmer groups in Jambi Province. The economic capital of the cattle farmer group is in the form of:cattle farming costs partially affect the development of farmer groups in Jambi Province.

\section{REFERENCES}

1. Bourdieu, Pierre. 1985 The Social Space and the Genesis of Groups. Social Science Information 24, 195-220.

2. Carpenter, JP, et al. 2004. Social Capital and Trust in South-east Asian Cities, Urban Studies 41 (4), 853-874.

3. Cohen, D. \& Prusak, L. 2001. In Good Company, Boston: Harvard Business School Press.

4. Coleman, JS 2000. Social Capital in the Creatian of Human Capital in P. Dasgupta and I.

5. Colletta, N. 1998. The Depletion of A Restoration of Social Capital In War-Torn Societies:

6. Fukuyama, F. 1995. Trust: The Social Virtues and Creation of Prosperity. New York: Free Press Paperbacks.

7. Grootaert, C. 2001. Does Social Capital Help the Poor?: A Synthesis of Findings from the Local Level Institutions Studies in Bolivia, Burkina Faso and Indonesia. Local Level Institutions Working Paper, 10. Social Development Department - The World Bank. Accessed from http://documents.worldbank.org/curated/en/ 368221468743373459/pdf/multiOpage.pdf.

8. Grootaert, C. and T. Van Bastelaer. 2002. Understanding and measuring Social Capital. Analysis: $1-320$

9. Harun Al Rashid. 1994. Sampling and Scaling Techniques. edited by Teguh Krismantoroadji et al., Postgraduate Program at Padjadjaran University, Bandung.

10. Hasbullah. 2006. Social Capital: Towards Excellence in Indonesian Human Culture. MRUnited Prees, Jakarta. 
11. Helliwel. JF 2006. "Well-being, Social Capital and Public Policy What's New?" in The Economic Journal. 116 (March)

12. Lin, N. 2001. Social Capital: A Theory of Social Structure and Action. USA: Cambridge University Press.

13. Narayan, D., \& Pritchett, L. (1999). Cents and Sociability: Household Income and Social Capital in Rural Tanzania. Economic Development and Cultural Change, 47(4), 871-897. DOI:https://doi.org/10.1086/452436.

14. Patrick, I., G. Marshall, I. Muktasam, and A. Ambarawati. 2006. Determining the role of social capital in linking smallholders with agribusiness. In: 50th annual conference of the Australian agricultural \& resource economic society, Manly Pacific Hotel, Sydney, Australia.

15. Putnam, R. 1993. The Prosperous Community: Social Capital and Community Life. The American Prospect 13 (1), 35-42

16. Putnam, R. 1995. Bowling Alone: America's Declining Social Capital. The Journal of Democracy, 6:1, p. 65-78

17. Rosana, EA, Saleh, and Hadiyanto. 2010. Communication barriers felt by farmers in fostering beef cattle cultivation in Ogal Ilir Regency. Journal of Development Communication February 2010. Vol. 08. No. 1. Pages: $27-41$.

18. Sawitri, D and IF Soepriadi. 2014. Farmers' social capital and industrial development in the agricultural center villages of Subang Regency and Karawang Regency. J. Planning and the City. 25(1):17-36.

19. Singarimbun, M. and Effendy. 1995. Survey Research Methods. LP3ES, Jakarta.

20. Stimson, RJ, Stough, RR, \& Roberts, BH 2006. Regional Economic Development: Analysis and Planning Strategies. Springer Verlag, Berlin Heidelberg

21. Syabra, R. 2003. Social Capital: Concepts and applications. Journal of Society and Culture. Vol.V. N0.1:1-5.

22. Tonkiss, F. 2000. Does Social Capital and Economy, in F. Tonkiss and A. Pasey (eds.) Trust and Civil Society. New York:St. Martin's

23. Vipriyanti, N, U. 2011. Social Capital \& Regional Development. Malang: Universitas Brawijaya Press.

24. Wijaya, M. 2007. Factors Affecting Disclosure of Social Responsibility in Manufacturing Companies Listed on the Indonesia Stock Exchange. Scientific Journal of Accounting Students. 1(1):26-30.

25. Woolcock, M. (1998). Social Capital and Economic Development: Toward A Theoretical Synthesis and Policy Framework. Theory and Society, 27(2), 151-208. DOI: https://doi.org/10.1023/A:1006884930135. 